\title{
Distribution of genetic diversity among disjunct populations of the rare forest understory herb, Trillium reliquum
}

\author{
E Gonzales ${ }^{1}$ and JL Hamrick ${ }^{2}$ \\ ${ }^{1}$ Department of Ecology, Evolution and Natural Resources, Rutgers University, New Brunswick, NJ 08901-8551, USA; ${ }^{2}$ Department of \\ Plant Biology and Department of Genetics, University of Georgia, Athens, GA 30602, USA
}

\begin{abstract}
We assessed genetic diversity and its distribution in the rare southeastern US forest understory species, Trillium reliquum. In all, 21 loci were polymorphic $\left(P_{\mathrm{S}}=95.5 \%\right)$ and the mean number of alleles per polymorphic locus was 3.05. However, genetic diversity was relatively low $\left(H_{\mathrm{es}}=0.120\right)$ considering the level of polymorphism observed for this outcrossing species. A relatively high portion of the genetic diversity $(29.7 \%)$ was distributed among populations. There was no relationship between population size and genetic diversity, and we did not detect significant inbreeding. These results are best explained by the apparent self-incompatibility of this species, its longevity and clonal reproduction. To address questions regarding the history of $T$. reliquum's rarity, we compared results for $T$. reliquum with that of its more common and partially sympatric congener, $T$. cuneatum.
\end{abstract}

Despite shared life history traits and history of land use, we observed significant genetic differences between the two species. Although T. cuneatum contains slightly lower polymorphism $\left(P_{\mathrm{s}}=85 \%\right)$, we detected significantly higher genetic diversity $\left(H_{\mathrm{es}}=0.217\right)$; most of its genetic diversity is contained within its populations $\left(G_{\mathrm{ST}}=0.092\right)$. Our results suggest that not only is there little gene flow among extant $T$. reliquum populations, but that rarity and population isolation in this species is of ancient origins, rather than due to more recent anthropogenic fragmentation following European colonization. The Chattahoochee River was identified as a major barrier to gene exchange.

Heredity (2005) 95, 306-314. doi:10.1038/sj.hdy.6800719; published online 10 August 2005

Keywords: genetic diversity; rarity; fragmentation; conservation; Trillium

\section{Introduction}

Natural populations often decline as a result of habitat deterioration caused by anthropogenic disturbance. A number of studies document that species become rare and endangered due to habitat loss, small population size and increased isolation of disjunct populations, or due to the detrimental impact of non-native animals and plants (Gemmill et al, 1998). Attempts to generalize these studies have been made repeatedly, but there are numerous exceptions and confounding factors that impede such endeavours (Karron, 1987; Hamrick and Godt, 1996; Gitzendanner and Soltis, 2000; Godt and Hamrick, 2001).

Dissecting the causes and consequences of rarity is often difficult. Species become rare by several means, and rarity is associated with a variety of evolutionary and ecological factors, including habitat specificity, local population size and geographic range (Rabinowitz, 1981). We address the genetic consequences of rarity in disjunct populations of Trillium reliquum Freeman (Relict trillium). This monocot species is a member of the Trilliaceae (sensu Dahlgren et al, 1985) or the Melanthiaceae (sensu APG, 1998). It is a forest understory spring

Correspondence: E Gonzales, Department of Ecology, Evolution and Natural Resources, Rutgers University, New Brunswick, NJ 08901-8551, USA. E-mail: gonzales@acsop.rutgers.edu

Received 7 February 2005; accepted 22 June 2005; published online 10 August 2005 ephemeral, with a narrow geographic range but broad habitat specificity - an unusual condition for rarity. T. reliquum has been only recently described; specimens collected prior to the species description were misidentified as T. decipiens or T. decumbens (Freeman, 1975). Although its historical geographic distribution is unknown, presumably, it has suffered greatly from human activities during the last three centuries, and extant populations are thought to represent remnants of a formerly more widespread distribution - hence the specific epithet reliquum (relict) (Freeman, 1975). Since its description and listing as endangered by the US Fish and Wildlife Service, about 30 additional populations have been identified. Most are small to moderate in size, isolated from one another, and are primarily restricted to the Fall Line Hills district from the Georgia-South Carolina border to south-western Georgia and southeastern Alabama (Figure 1).

Several life-history traits of $T$. reliquum may affect the genetic response of its populations to habitat disturbance and loss. It is self-incompatible in some populations or has a leaky self-incompatible system (M Brooks personal communication, Ch. Heckel, personal communication). It is polycarpic and reproduces infrequently, both by seeds and clonal spread. Trillium species typically require more than 10 years to reach the reproductive stage (Ohara, 1989; Jules, 1996, pers obs). Individual genets may persist for decades. T. reliquum is pollinated by weak-flying insects (Calliphoridae flies and beetles) (M Brooks, 


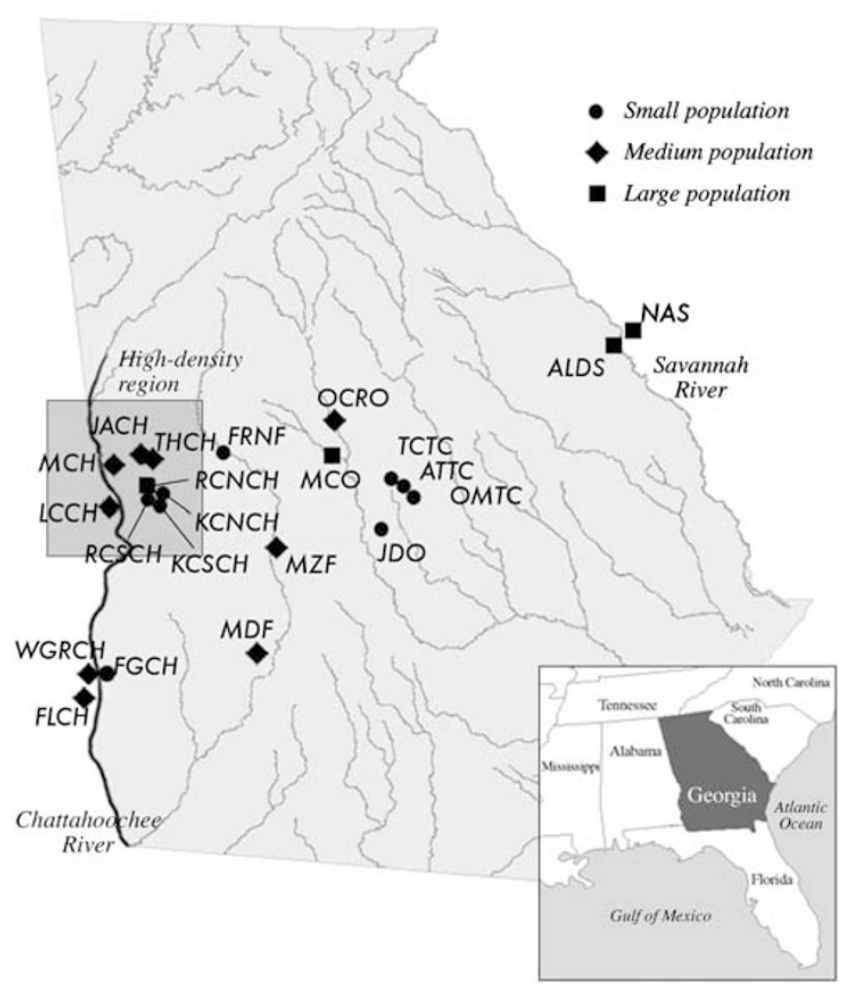

Figure 1 Distribution of sampled Trillium reliquum populations. The Chattahoochee River is indicated in bold and the region of high population density is indicated by the shaded area in the NW portion of $T$. reliquum range.

personal communication). Trillium, like many forest understory herbs, is myrmecochorous; seeds are primarily dispersed by ants or passively by gravity. We have observed yellow jackets (Vespula vulgaris) foraging inside mature fruits, and they may act as less common dispersers. Similarly, Jules (1996) reported V. vulgaris dispersing seeds of the related species, T. ovatum. Populations of $T$. reliquum are typically located along rivers with individual plants scattered on flood plains and bluffs; giving rise to the possibility that seeds may, in rare instances, be moved along watersheds during seasonal floods.

In this study, we examine the distribution of genetic variation within and among populations of T. reliquum at several spatial scales. Additionally, we surveyed populations of its common congener, $T$. cuneatum, in their sympatric geographic range to yield insights into the history of population distribution and the genetic consequences of fragmentation. Such comparisons are useful because populations of both species were subjected to the same human pressures in areas of sympatry, and they have similar life-history characteristics, habitats, pollinators and seed dispersers. Comparisons are based on the expectation that if $T$. reliquum populations were disjunct prior to anthropogenic fragmentation, the genetic structure of its populations would be greater than that of the more common (albeit also fragmented) T. cuneatum in the same region. In addition, we analyzed relationships between genetic diversity and population size, geographic distance and watershed association. The proximity of $T$. reliquum populations to rivers may facilitate rare seed dispersal events and may provide corridors for pollinators to follow. Consequently, populations within the same river basin should be more genetically similar than nearby populations belonging to different watersheds.

Populations of $T$. reliquum are widely scattered, disjunct, presumably remnant sites of a previously more common, continuously distributed species (Freeman, 1975). Population genetics theory predicts that such populations, if isolated by recent habitat fragmentation due to anthropogenic development, would retain the genetic 'footprint' of this history and we should detect an isolation-by-distance pattern. Alternatively, if populations were disjunct prior to European settlement, they should be significantly differentiated with no discernable pattern of genetic structure. The overall distribution of genetic diversity should be haphazard due to long-term isolation without any apparent gene flow among populations. Additionally, if $T$. reliquum populations were historically isolated, we might expect to find evidence of unique or otherwise rare alleles at relatively high frequencies in isolated populations. Combined, species level statistics estimating genetic diversity within this species should be considerably higher than mean population values. We use genetic diversity comparisons with its more common congener, T. cuneatum, to gain further insights into the history of rarity of T. reliquum. If T. reliquum was common prior to European colonization and agricultural spread, we should see similar genetic differentiation among populations of both species since both were exposed to similar anthropogenic pressures. Alternatively, if $T$. reliquum's rarity is more ancient, we would expect stronger differentiation among remnant populations of $T$. reliquum relative to that for T. cuneatum.

Finally, we also address the question of associations between the density of populations and genetic diversity. The north-western portion of $T$. reliquum's geographic distribution has a higher density of populations than the rest of its range (Figure 1). As a result, we expect to find a relationship between interpopulation distance and the ability to retain genetic diversity in this region, particularly when allele frequencies and heterozygosity are considered. Closely distributed populations may better counteract genetic drift than widely separated, disjunct populations. In addition, smaller populations should experience greater risk of genetic diversity loss, both in terms of allelic richness and heterozygosity as well as higher levels of inbreeding.

\section{Materials and methods}

\section{Sampling}

We sampled 48 plants (at least $10 \mathrm{~m}$ apart to avoid collecting ramets of clonal individuals) from each of $22 \mathrm{~T}$. reliquum sites, representing two-thirds of all extant populations throughout its geographic range (Figure 1). Samples were collected at the peak of flowering. Although we did not quantify precise population sizes, we grouped populations according to their estimated number of flowering individuals at the time of sampling into three relative size classes: small $(<50$ flowering individuals), moderate (50-200 flowering individuals), and large ( $>200$ flowering individuals). Additionally, for comparative purposes, we collected samples from nine 
T. cuneatum populations from approximately the same geographic area; in five cases (KCNCH, LLCH, MCH, $\mathrm{MCO}$ and $\mathrm{RCNCH}$ ) individuals of both species occur intermingled within the same site; the remaining four T. cuneatum populations are monospecific; two of these (TGA, HGA) are located near $T$. reliquum populations, and the final two (CHAT, SAL) are more distant to ensure comparable spatial sampling for both species. Precise geographic coordinates were recorded for each site, which allowed us to determine distances between all pairs of populations using ArcView 3.3 software (ESRI, 2002). Distances between T. reliquum populations ranged from 1.2 to $362.5 \mathrm{~km}$ with a mean of $130 \mathrm{~km}$ $(\mathrm{SD}=77.8 \mathrm{~km})$. Similarly, T. cuneatum sites were distributed over $6.2-306 \mathrm{~km}$, with a mean distance of $115.2 \mathrm{~km}$ $(\mathrm{SD}=88.9 \mathrm{~km})$. Detailed location information may be requested from the Georgia Department of Natural Resources. Voucher specimens are deposited in the University of Georgia Herbarium (GA).

\section{Genetic analyses}

We transported leaf samples on ice to the laboratory and crushed them within $24 \mathrm{~h}$ using a mortar and pestle. An extraction buffer (Wendel and Parks, 1982) was added to solubilize and stabilize enzymes. The extract was absorbed onto chromatography paper wicks and stored at $-70^{\circ} \mathrm{C}$ until electrophoretic analyses. We used starch gel electrophoresis to determine allozyme diversity. We resolved a subset of the following enzymes for each species: amino-acid transferase (AAT), diaphorase (DIA), fluorescent esterase (FE), glutamate dehydrogenase (GDH), isocitrate dehydrogenase (IDH), leucineamino peptidase (LAP); malate dehydrogenase (MDH), menadione reductase (MNR), 6-phosphogluconate dehydrogenase (6-PGDH), peroxidase (PER), phosphoglucoisomerase (PGI), phosphogluco-mutase (PGM), shikimate dehydrogenase (SKDH), triose-phosphate isomerase (TPI), UTP-glucose-1-phosphate (UGPP). For T. reliquum, we employed the following four gel-electrode buffer combinations to resolve 22 loci on $11 \%$ starch gels: Buffer 7: (AAT); Buffer 8: (DIA, FE-1, FE-2, FE-3, GDH, LAP, MNR, TPI-1, TPI-2), Buffer 4: (IDH, MDH-1, MDH-2, MDH-3, 6-PGDH-1，6-PGDH-3， SKDH-1， SKDH-2, UGPP); and Buffer 6: (PER, PGI-1, PGI-2). For $T$. cuneatum, we employed five gel-electrode combinations and resolved the following 20 loci: Buffer 8: (AAT-2, AAT-3, GDH); Buffer 4: (IDH, SKDH-1, SKDH-2, UGPP1, UGPP-2); Buffer 6: (DIA, FE-1, FE-2, FE-3, FE-4, PER, TPI-1, TPI-2); Buffer 11: (MDH-1, MDH-2, 6-PGDH, PGM). Stain recipes for AAT, DIA and MNR are given in Cheliak and Pitel (1984); UGPP is given in Manchenko (1994). All other stain and buffer recipes were taken from Soltis et al (1983). For enzymes with more than one locus, loci were numbered sequentially with the number one assigned to the most anodal locus.

\section{Statistical analyses}

We calculated genetic diversity statistics for both species (as described in Hamrick and Godt, 1989) and for each population (as described in Hedrick, 1985) using a program developed by MD Loveless and A Schnabel. These measures included the percentage of polymorphic loci $(P)$, the mean number of alleles per locus $(A)$, and per polymorphic locus $(A P)$, the effective number of alleles
$\left(A_{\mathrm{e}}\right)$, and observed $\left(H_{\mathrm{o}}\right)$ and expected $\left(H_{\mathrm{e}}\right)$ heterozygosity. We tested the difference in mean heterozygosity for both species using the unbiased estimator of Nei and Chesser (1983). Variance estimates for $H_{\mathrm{e}}$ were calculated by the jackknife procedure of Weir and Cockerham (1984). We also calculated a coefficient of variation $\left(C V_{\mathrm{He}}\right)$ for expected population heterozygosity values (as in Schoen and Brown, 1991). Subscript $s$ indicates species values, whereas $p$ indicates population values. Deviations from Hardy-Weinberg expectations were examined for each polymorphic locus within each population by calculating Wright's fixation index (Wright, 1922). Fixation indices were tested for significance using a $\chi^{2}$ test (Li and Horvitz, 1953).

We estimated population divergence using Nei's gene diversity statistics (Nei, 1973, 1977). This statistic $\left(G_{\mathrm{ST}}\right)$ estimates the proportion of the total genetic diversity $\left(H_{\mathrm{T}}\right)$ found among populations for each polymorphic locus; $G_{\text {ST }}$ values were averaged across loci to obtain an overall estimate of population divergence. In addition, we calculated mean $G_{\mathrm{ST}}$ values for loci with $H_{\mathrm{T}}$ greater than 0.10 because loci with one common allele and remaining rare alleles are less informative concerning genetic structure. Each $G_{\mathrm{ST}}$ value was tested for significance by a $\chi^{2}$ test (Workman and Niswander, 1970). Nei (1977) demonstrated that $G_{\mathrm{ST}}$ is equivalent to a multiallelic $F_{\mathrm{ST}}$ (Wright, 1951). Chakraborty and Danker-Hopfe (1991) have also shown that these two indices are empirically equivalent to Weir and Cockerham's (1984) $\theta$ when sample sizes are equal and a large number of populations are analyzed as is the case for this study. Additionally, to examine differentiation among populations, we conducted pairwise $F_{\mathrm{ST}}$ tests for all populations obtained by permutations using software GenAlEx 6.0 available at http://www.anu.edu.au/BoZoGenAlEx (Peakall and Smouse, 2005). Genetic identity (I) and distance (D) measures were also calculated for each pairwise combination of populations (Nei, 1972). To graphically portray genetic relationships between $T$. reliquum populations, we used genetic distances to construct a UPGMA phenogram as well as a Neighbour Joining tree using NTSYS-pc 2.1 software (Rohlf, 1992).

Finally, to gain insights into patterns of genetic diversity across the species range, we subdivided $T$. reliquum populations based on three factors. We investigated the effects of interpopulation distance, population size and watershed association on the populations' ability to retain genetic variation. In addition, we used Rousset's (1997) measure of genetic distance $F_{\mathrm{ST}} /\left(1-F_{\mathrm{ST}}\right)$ to analyze associations between log-transformed geographic distance and genetic distance, using a reduced major axis regression (Sokal and Rohlf, 1981); this test assesses whether the pairwise population genetic differentiation matrix is correlated with the pairwise geographic distance matrix. Significance of the correlation between genetic and geographic distance was tested with a Mantel test. Analyses were executed using Isolation by Distance software (Bohonak, 2002). We also subdivided the range of $T$. reliquum according to the density of populations per geographic area (Figure 1) to investigate the effect of interpopulation distances on the distribution of genetic variation. The north-western portion of $T$. reliquum's range has a higher density of populations with a mean interpopulation distance of $21.1 \mathrm{~km}$ (additional, unsampled populations exist in this region), while the 
remaining populations are more scattered with a mean interpopulation distance of $138.3 \mathrm{~km}$.

\section{Results}

Genetic diversity within the species

A total of 21 of the 22 loci resolved (95.5\%) were polymorphic in at least one $T$. reliquum population (Table 1); slightly lower number, 17 of the 20 loci $(85 \%)$ were polymorphic in T. cuneatum populations (Table 2). At the species level, we detected fewer alleles per polymorphic locus $\left(A P_{s}\right)$ and alleles per locus $\left(A_{s}\right)$ in T. reliquum than in $T$. cuneatum (T. reliquum: $\mathrm{AP}_{s}=3.05$, $A_{s}=2.95 ;$ T. cuneatum: $\left.\mathrm{AP}_{s}=3.71, A_{s}=3.30\right)$. For $T$. reliquum, the mean effective number of alleles $\left(A_{\mathrm{es}}=1.16\right)$ was low considering its $P_{s}, \mathrm{AP}_{s}$ and $A_{s}$ values, and again, it was lower than the values for T. cuneatum $\left(A_{\mathrm{e}}=1.39\right)$. Similarly, $T$. reliquum genetic diversity was also low $\left(H_{\mathrm{es}}=0.120\right)$ relative to its level of polymorphism and the number of alleles detected (Table 1) and relative to T. cuneatum $\left(H_{\mathrm{es}}=0.217\right)$. Gene frequency values can be obtained from EG upon request.

\section{Genetic diversity within populations}

We detected even more striking genetic diversity differences between the two species at the population level. The mean percentage of polymorphic loci $\left(P_{p}\right)$ averaged $33.9 \%$ across all T. reliquum populations, while T. cuneatum populations average $58.3 \%$ polymorphic loci. For $T$. reliquum, all of the within population statistics had lower values than $T$. cuneatum. The mean number of alleles per locus $\left(A_{p}\right)$ was 1.41 and 1.89 , respectively, with

Table 1 Genetic diversity statistics for T. reliquum populations

\begin{tabular}{|c|c|c|c|c|c|c|c|c|c|}
\hline Population & Drainage & Pop Size & $\mathrm{P}_{\mathrm{p}}(\%)$ & Total $\mathrm{A}_{\mathrm{p}}$ & $\mathrm{AP}_{\mathrm{p}}$ & $\mathrm{A}_{e p}$ & $\mathrm{H}_{e p}$ & $\mathrm{H}_{o p}$ & Mean I \\
\hline NAS-SC & Savannah & $\mathrm{L}$ & 45.5 & 35 & 2.30 & 1.21 & 0.120 & 0.119 & 0.957 \\
\hline ALDS-GA & Savannah & $\mathrm{L}$ & 36.4 & 34 & 2.50 & 1.23 & 0.126 & 0.119 & 0.927 \\
\hline OMTC-GA & Oconee & $S$ & 45.5 & 34 & 2.20 & 1.14 & 0.088 & 0.113 & 0.893 \\
\hline ATTC-GA & Oconee & $S$ & 45.5 & 36 & 2.40 & 1.21 & 0.126 & 0.123 & 0.937 \\
\hline TCTC-GA & Oconee & $S$ & 31.8 & 30 & 2.14 & 1.15 & 0.089 & 0.080 & 0.928 \\
\hline EPOCM-GA & Ocmulgee & $\mathrm{M}$ & 31.8 & 31 & 2.29 & 1.16 & 0.092 & 0.093 & 0.962 \\
\hline MCOM-GA & Ocmulgee & $\mathrm{L}$ & 13.6 & 25 & 2.00 & 1.07 & 0.043 & 0.045 & 0.926 \\
\hline JDOCM-GA & Ocmulgee & $S$ & 22.7 & 27 & 2.00 & 1.09 & 0.048 & 0.045 & 0.893 \\
\hline FRNF-GA & Flint & $S$ & 50.0 & 34 & 2.09 & 1.16 & 0.100 & 0.111 & 0.950 \\
\hline MZF-GA & Flint & M & 22.7 & 28 & 2.20 & 1.07 & 0.041 & 0.041 & 0.953 \\
\hline MDF-GA & Flint & M & 4.6 & 23 & 2.00 & 1.04 & 0.020 & 0.016 & 0.922 \\
\hline MCH-GA & Chattahoochee & M & 40.9 & 34 & 2.33 & 1.09 & 0.071 & 0.073 & 0.965 \\
\hline THCH-GA & Chattahoochee & M & 40.9 & 33 & 2.22 & 1.06 & 0.051 & 0.045 & 0.965 \\
\hline JACH-GA & Chattahoochee & $\mathrm{M}$ & 40.9 & 33 & 2.22 & 1.05 & 0.040 & 0.038 & 0.965 \\
\hline RCNCH-GA & Chattahoochee & $\mathrm{L}$ & 36.4 & 31 & 2.13 & 1.07 & 0.050 & 0.040 & 0.963 \\
\hline RCSCH-GA & Chattahoochee & $S$ & 31.8 & 29 & 2.00 & 1.08 & 0.058 & 0.043 & 0.963 \\
\hline KCNCH-GA & Chattahoochee & $S$ & 40.9 & 32 & 2.11 & 1.08 & 0.057 & 0.052 & 0.961 \\
\hline KCSCH-GA & Chattahoochee & S & 22.7 & 27 & 2.00 & 1.03 & 0.026 & 0.026 & 0.966 \\
\hline FGCH-GA & Chattahoochee & $S$ & 22.7 & 28 & 2.20 & 1.04 & 0.028 & 0.030 & 0.964 \\
\hline LCCH-AL & Chattahoochee & M & 59.1 & 38 & 2.23 & 1.13 & 0.097 & 0.099 & 0.918 \\
\hline WGRCH-AL & Chattahoochee & M & 22.7 & 29 & 2.40 & 1.14 & 0.076 & 0.097 & 0.923 \\
\hline FLCH-AL & Chattahoochee & M & 36.4 & 31 & 2.13 & 1.12 & 0.067 & 0.084 & 0.926 \\
\hline
\end{tabular}

Populations are ordered in east-west direction and grouped according to their association with watersheds. The last two letters in each population's name designate a state $(\mathrm{SC}=$ South Carolina; GA = Georgia; $\mathrm{AL}=\mathrm{Alabama})$. East-west division is indicated by a line between GA and AL populations.

$P_{p}=$ percent of polymorphic loci; Total $A_{p}=$ total number of alleles per population (including monomorphic loci); $A P_{p}=$ mean number of alleles per polymorphic locus; $A_{\mathrm{e}}=$ mean effective number of alleles per polymorphic locus; $H_{\mathrm{e} p}=$ genetic diversity (expected heterozygosity); $H_{\mathrm{o} p}=$ observed heterozygosity; $\mathrm{I}=$ genetic identity.

Table 2 Genetic diversity statistics for T. cuneatum populations

\begin{tabular}{|c|c|c|c|c|c|c|c|}
\hline Population & $\mathrm{P}_{\mathrm{p}}(\%)$ & Total $\mathrm{A}_{\mathrm{p}}$ & $\mathrm{AP}_{\mathrm{p}}$ & $\mathrm{A}_{e p}$ & $\mathrm{H}_{e p}$ & $\mathrm{H}_{o p}$ & Mean I \\
\hline MCO-GA & 55.0 & 39 & 2.73 & 1.38 & 0.193 & 0.161 & 0.968 \\
\hline MCH-GA & 50.0 & 36 & 2.60 & 1.80 & 0.201 & 0.201 & 0.958 \\
\hline TGA-GA & 65.0 & 38 & 2.38 & 1.33 & 0.187 & 0.183 & 0.967 \\
\hline HGA-GA & 75.0 & 42 & 2.47 & 1.41 & 0.226 & 0.211 & 0.954 \\
\hline RCNCH-GA & 50.0 & 34 & 2.40 & 1.3 & 0.152 & 0.158 & 0.967 \\
\hline KCNCH-GA & 55.0 & 38 & 2.82 & 1.36 & 0.186 & 0.177 & 0.963 \\
\hline CHAT-GA & 55.0 & 33 & 2.18 & 1.25 & 0.154 & 0.147 & 0.969 \\
\hline LCCH-AL & 60.0 & 40 & 2.75 & 1.39 & 0.203 & 0.197 & 0.946 \\
\hline SAL-AL & 60.0 & 37 & 2.50 & 1.42 & 0.229 & 0.211 & 0.962 \\
\hline
\end{tabular}

Populations were sampled approximately in geographic regions sympatric with T. reliquum. The last two letters in each population's name designate a state (GA = Georgia; $\mathrm{AL}=$ Alabama)

$P_{p}=$ percent of polymorphic loci; Total $A_{p}=$ total number of alleles per population (including monomorphic loci); $\mathrm{AP} p=$ mean number of alleles per polymorphic locus; $A_{\mathrm{e}}=$ mean effective number of alleles per polymorphic locus; $H_{\mathrm{e} p}=$ genetic diversity (expected heterozygosity); $H_{\mathrm{o} p}=$ observed heterozygosity; I = genetic identity. 
a mean of 2.19 and 2.54 alleles per polymorphic locus $\left(A P_{p}\right)$, and 1.11 and 1.36 effective alleles per locus $\left(A_{\mathrm{e} p}\right)$. In $T$. reliquum, mean genetic diversity $\left(H_{\mathrm{e} p}\right)$ and observed heterozygosity $\left(H_{\mathrm{o} p}\right)$ were 0.069 and 0.070 , respectively (Table 1), while genetic diversity in T. cuneatum populations was significantly $(P<0.001)$ higher $\left(H_{\mathrm{e} p}=0.192\right.$, $H_{\mathrm{o} p}=0.183$ ) (Table 2). Observed genotype frequencies conformed to Hardy-Weinberg expectations for $88.4 \%$ of the loci in all $T$. reliquum populations. We detected 19 instances $(11.6 \%)$ of $F_{\text {IS }}$ values that differ significantly from zero $(P<0.05)$; three cases with heterozygote excesses and 16 cases with heterozygote deficiencies. Significant $F_{\text {IS }}$ values were mostly attributable to loci with $H_{\mathrm{S}}<0.10$ (17 of 19 cases), that is loci that are not very informative concerning genotype equilibrium distributions. The mean $F_{\text {IS }}$ value across all loci and populations was 0.007 and did not differ significantly from zero.

\section{Genetic diversity among populations}

Genetic diversity varied substantially more among T. reliquum populations than among $T$. cuneatum populations. Allele frequencies were significantly different among $T$. reliquum populations for 20 of 21 polymorphic loci, and for 16 of 17 polymorphic loci among T. cuneatum populations $(P<0.001)$. For $T$. reliquum, values of $P_{p}$ ranged from 4.6 to $59.1 \%$, and $H_{\mathrm{e} p}$ values ranged from 0.020 to $0.126(\mathrm{CV}=0.468)$, while we observed much less variation among $T$. cuneatum populations (range of $\left.P_{p}=55-75 \%\right)$ and higher $H_{\mathrm{e} p}(0.152-0.221$, $\mathrm{CV}=0.140$ ). $T$. reliquum populations at either margin of the geographic range (ie eastern- and western-most) had the highest proportion of polymorphic loci. A statistically significant trend of decreasing heterozygosity from east to west $(r=0.436, P<0.001)$ was detected with the notable exception of the three Alabama populations (LCCH, WGRCH and FLCH), west of the Chattahoochee River. After excluding these three populations from analyses, the 'east-west' trend in heterozygosity was much stronger $(r=0.704, P<0.001)$. A similar trend was observed for the effective number of alleles $\left(A_{\mathrm{e} p}\right)$ while $P_{p}, \mathrm{AP}_{p}$ and $A_{p}$ varied haphazardly and without obvious trends. We did not observe such a pattern in T. cuneatum. We identified a relatively high, but comparable number of private alleles (12 for T. reliquum, mean frequency $=0.089 ; 14$ for $T$. cuneatum, mean frequency $=0.067$ ). A disproportionate number (six) of the $T$. reliquum private alleles were found in the three Alabama populations (LCCH, WGRCH and FLCH). Similarly, five of the T. cuneatum private alleles were detected in the two Alabama populations (LCCH, SAL).

The proportion of total genetic variation attributable to differentiation among $T$. reliquum populations $\left(G_{\mathrm{ST}}\right)$, was 0.297; values for individual loci ranged from 0.010 to 0.797. Hierarchical analyses indicated that grouping populations by watersheds explains $45 \%$ of the total differentiation among populations (ie $G_{\mathrm{ST}}$ among watersheds $=0.133)$. We also calculated $G_{S T}$ values for the 10 loci with $H_{\mathrm{T}}>0.10$ resulting in an unusually high $G_{\mathrm{ST}}$ value (0.436) for an outcrossing species. Mean genetic identity was moderate $(I=0.942)$ with a fairly broad range of values (0.841-0.999). In sharp contrast, only $9.2 \%$ of total genetic variation was distributed among populations of T. cuneatum; when loci with $H_{\mathrm{T}}>0.10$ are considered, GST values increased to 0.11 .

\section{Geographic patterns of genetic variation in $T$. reliquum}

Geographically close populations exhibited a weak trend of higher genetic similarities. Although the isolation by distance analysis resulted in a statistically significant correlation, only a very small portion of the among population differentiation was explained by geographic distance $\left(r^{2}=0.083, P<0.004\right)$. In spite of the overall 'isolation by distance' trend, some populations separated by short geographic distances had relatively large genetic distance values. Such population pairs invariably belonged to different watersheds (eg JDOCM and $\mathrm{MCH}$ ).

We used Nei's genetic distances for UPGMA and Neighbor Joining classification analyses; only the UPGMA tree is presented (Figure 2). Both phenograms depicted distinct groups of populations belonging to the same river basin (eg the North Chattahoochee watershed in Georgia), while other populations (eg MZF and EPOCM) clustered in the phenogram despite no apparent watershed or other geographical association. The three Alabama populations (LCCH, FLCH and WGRCH) located along the western bank of the Chattahoochee River did not cluster with nearby populations on the Georgia side of the river. Moreover, the Georgia FGCH site is included in the clade of populations belonging to the northern portion of this watershed, rather than with

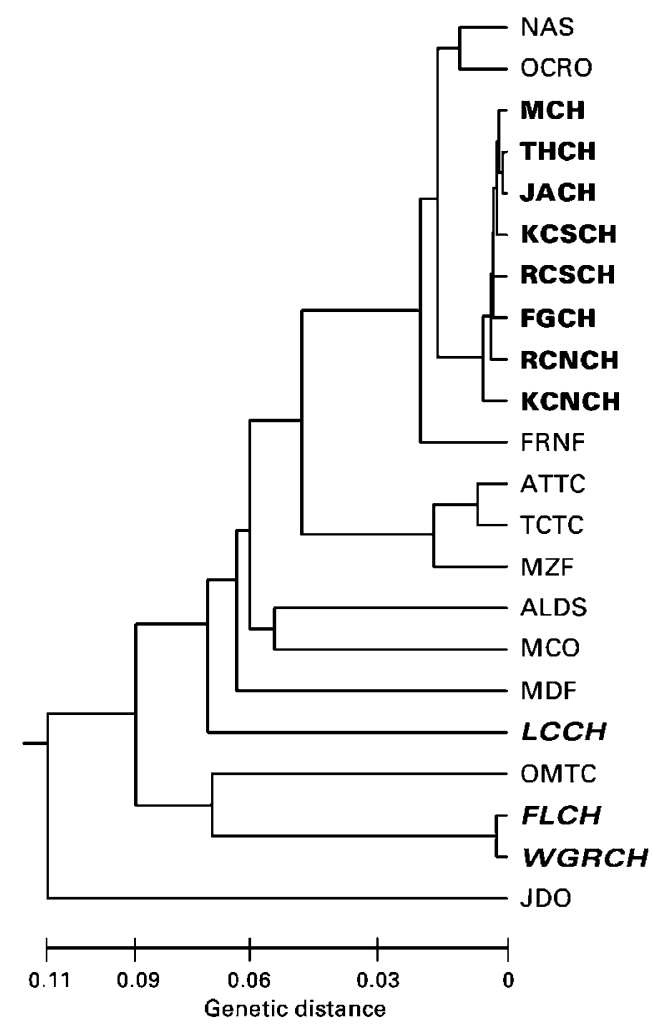

Figure 2 UPGMA phenogram based on Nei's (1972) genetic distance values for 22 sampled T. reliquum populations. See Table 1 and Figure 1 for state and drainage locations. The Georgia populations associated with the Chattahoochee River drainage are indicated in bold, while the three Alabama populations are italicized. 
nearby populations WGRCH and FLCH just to the west across the Chattahoochee River.

To further investigate patterns of genetic variation, we divided the geographic range of $T$. reliquum into two subregions: The north-western portion of the distribution (Figure 1) contains seven populations with relatively small geographic distances among them; and the eastcentral portion with 15 populations more widely scattered across T. reliquum's range. The mean percentage of polymorphic loci per population $\left(P_{p}\right)$ detected in the high-density area was $36.4 \%$, while the mean value for more widely scattered populations was $30.4 \%$. The mean number of alleles per locus $\left(A_{p}\right)$ in the high density area was 1.42 (Table 2), slightly higher than in the low-density region $(A=1.38)$. Although populations in close proximity retained a higher percentage of polymorphic loci and more alleles per locus, not all measures in this region indicated higher genetic diversity. The mean number of alleles per polymorphic locus $\left(A P_{p}\right)$ was 2.14 in the highdensity region, while populations separated by larger distances average 2.21 alleles per polymorphic locus. Populations from areas of high density had on average 1.07 and the more scattered populations 1.13 effective number of alleles, and genetic diversity $\left(H_{\mathrm{e}}\right)$ of 0.05 and 0.08 respectively (Table 3 ). There were no significant differences among the population size categories for any of the genetic diversity parameters, although we found a weak inverse relationship between the mean percentage of polymorphic loci and population size (Table 3).

\section{Discussion}

\section{Genetic diversity within the species}

T. reliquum maintains unusually high levels of genetic polymorphism despite its rarity and disjunct distribution (Table 1). The strikingly incongruent characteristic, however, is the low genetic diversity observed for $T$. reliquum $\left(H_{\mathrm{es}}=0.120\right)$ relative to the percentage of polymorphic loci (95\%) and the number of alleles per polymorphic locus (3.05) (Table 1). This discordance between genetic diversity $\left(H_{\mathrm{e}}\right)$ and polymorphism is best explained by the relatively low effective number of alleles per locus $\left(A_{\mathrm{e}}=1.16\right)$. This low value results from the high number of low-frequency alleles detected for many loci. Six (29\%) of the polymorphic loci have overall heterozygosity $\left(H_{\mathrm{T}}\right)$ values below 0.05 and another five (24\%) have $H_{\mathrm{T}}$ values less than 0.10 .

$T$. reliquum has a slightly higher proportion of polymorphic loci than its more common congener, $T$. cuneatum, while the remaining population genetic statistics were appreciably higher for $T$. cuneatum (Table 4). Although rare species usually maintain less polymorphism, this generalization does not always hold (Karron, 1987; Godt and Hamrick, 2001). In fact, Gitzendanner and Soltis (2000) found that approximately $20 \%$ of the rare species reviewed contain equal or higher polymorphism than their more common congeners. Our results, however, are consistent with the majority of the congeneric comparisons reviewed by Gitzendanner and

Table 3 Comparison of mean genetic diversity statistics for T. reliquum populations based on their interpopulation distance, and population size: Area with a high density of populations (mean distance among populations $=21.1 \mathrm{~km}$ ); and area with low density (mean distance $=138.3 \mathrm{~km}$ ). Populations were also grouped into relative size categories based on the number of flowering plants

\begin{tabular}{|c|c|c|c|c|c|c|c|}
\hline & No. of sampled populations & $\mathrm{P}_{\mathrm{p}}$ & $A P_{\mathrm{p}}$ & $A_{p}$ & $\mathrm{~A}_{\mathrm{e}}$ & $\mathrm{H}_{e p}$ & $\mathrm{H}_{o p}$ \\
\hline High-density subregion & 8 & 36.4 & 2.14 & 1.42 & 1.07 & 0.070 & 0.052 \\
\hline Low-density subregion & 14 & 30.4 & 2.21 & 1.38 & 1.13 & 0.140 & 0.081 \\
\hline Large populations $(>200)$ & 4 & 33.0 & 2.23 & 1.42 & 1.15 & 0.085 & 0.0 \\
\hline Moderate populations (50-200) & 9 & 33.3 & 2.22 & 1.42 & 1.10 & 0.062 & 0.0 \\
\hline Small populations $(<50)$ & 9 & 34.9 & 2.13 & 1.40 & 1.11 & 0.069 & 0.069 \\
\hline
\end{tabular}

Table 4 Species level genetic diversity comparisons for T. reliquum, its more common congener T. cuneatum, south-eastern rare and endemic species, outcrossing perennials, monocots and all seed plants

\begin{tabular}{|c|c|c|c|c|c|c|}
\hline Taxonomic group & $\mathrm{P}(\%)$ & $\mathrm{AP}$ & A & $\mathrm{A}_{e}$ & $\mathrm{H}_{e}$ & $\mathrm{G}_{S T}$ \\
\hline T. reliquum & 95.5 & 3.05 & 2.95 & 1.16 & 0.120 & 0.279 \\
\hline Mean population values (SD) & $33.9(12.8)$ & $2.19(0.14)$ & $1.41(0.17)$ & $1.11(0.06)$ & $0.069(0.032)$ & - \\
\hline Range & $4.6-59.1$ & $2.00-2.50$ & $1.05-1.73$ & $(1.03-1.23)$ & $0.126-0.20$ & - \\
\hline T. cuneatum & 85 & 3.71 & 3.3 & 1.36 & 0.217 & 0.092 \\
\hline Mean population values (SD) & $58.33(3.63)$ & $2.54(0.21)$ & $1.89(0.15)$ & $1.36(0.06)$ & $0.183(0.016)$ & - \\
\hline Range & $50.0-75$ & $2.18-2.82$ & $(1.65-2.10)$ & $1.25-1.42$ & $0.152-0.229$ & - \\
\hline Rare southeastern plants ${ }^{a}$ & $46.7(4.5)$ & $2.74(0.09)$ & $1.87(0.13)$ & - & $0.123(0.017)$ & - \\
\hline SE endemics ${ }^{\mathrm{b}}$ & $40.0(3.2)$ & - & $1.8(0.08)$ & - & $0.096(0.01)$ & - \\
\hline Perennials (outcrossing) ${ }^{c}$ & 43.7 & - & - & - & 0.18 & 0.218 \\
\hline Monocots (outcrossing) & 52.5 & - & - & - & 0.165 & 0.157 \\
\hline All plants $\mathrm{d}$ & $52.2(1.0)$ & - & $1.99(0.03)$ & - & $0.153(0.004)$ & $0.225(0.009)$ \\
\hline
\end{tabular}

Standard errors are in parentheses where available.

aGodt and Hamrick, 2001.

'Hamrick and Godt, 1989.

cHamrick and Godt, 1996.

${ }^{\mathrm{d}}$ Godt and Hamrick, 1998 
Soltis (2000) since they demonstrate a large discrepancy in genetic diversity between T. reliquum $\left(H_{\mathrm{es}}=0.120\right)$ and T. cuneatum $\left(H_{\mathrm{es}}=0.217\right)$.

\section{Genetic diversity within populations}

In contrast to the high polymorphism within species, T. reliquum populations maintain less genetic diversity, relative to its widespread congener. In this regard, T. reliquum's population values are more typical of other rare herbaceous perennials (Table 4). However, while Ellstrand and Elam (1993) reported that rare species often exhibit large discrepancies between mean observed and expected heterozygosities, we observed few such differences. We detected little inbreeding in any of the populations regardless of population size or isolation from nearest neighbouring populations $\left(F_{\mathrm{IS}}=0.007\right)$. The most likely explanation for the low inbreeding observed is the apparent self-incompatible or leaky SI breeding system of the species (M Brooks, personal communication).

A relatively large portion of the geographically restricted $T$. reliquum genetic diversity was partitioned among its populations (eg $G_{\mathrm{ST}}=0.279$ for all loci and 0.436 for loci with $H_{\mathrm{T}}>0.1$ ). This strong genetic differentiation is in sharp contrast to its more widespread congener sampled from a comparable geographic range. Most of the total genetic variation in T. cuneatum, is contained within populations $\left(G_{\mathrm{ST}}=0.092 ; G_{\mathrm{ST}}=0.110\right.$ for loci with $H_{\mathrm{T}}>0.10$ ). Several studies of allopatric Trillium species reported variable levels of genetic diversity and its distribution (eg Bayer et al, 1987; Whitkus et al, 1987; Tomimatsu and Ohara, 2003; Griffin and Barrett, 2004). $G_{\mathrm{ST}}$ values (or its analogs $F_{\mathrm{ST}}$ and $\theta$ ) reported in these studies ranged from 0.095 to 0.35 . However, populations of these Trillium species have been subjected to vastly different histories; some studies sampled from partially or completely glaciated regions in North America, some contain multiple glacial-refugial lineages and for some species monomorphic loci were not analyzed. As a result comparisons of these species with our results are not appropriate to address our question of the history of rarity in T. reliquum.

The high variation in genetic diversity and proportion of polymorphic loci among populations of T. reliquum (Table 1) is characteristic either of species with naturally disjunct ranges (Hamrick and Godt, 1996; Hamrick, 2004), or self-pollinated species (Schoen and Brown, 1991). However, even in perennial herbs with widely disjunct populations, for example Tradescantia hirsuticaulis (Godt and Hamrick, 1993) a granite outcrop endemic with a similar geographic range to $T$. reliquum, or Sarracenia leucophylaf (Wang et al, 2004), another relatively rare southeastern perennial herb, such extreme population variability in genetic diversity is uncommon. In contrast, Tomimatsu and Ohara (2003) reported comparable levels of both species and population genetic diversity in Trillium camschatcense in eastern Hokaido, Japan. In their study area, previously large, continuous populations had been fragmented into smaller remnants. Their investigation revealed that $91 \%$ of its loci were polymorphic (range 18-82\%); and $H_{\mathrm{e} p}$ was relatively low (0.079; range $0.035-0.133$ ). The relatively low level of differentiation among populations of $T$. camschatcense $\left(F_{\mathrm{ST}}=0.13\right)$ was similar to that of T. cuneatum.

Contrary to the $T$. camschatcense investigation (Tomimatsu and Ohara, 2003) and to our expectations, our study did not reveal a significant relationship between the size of $T$. reliquum populations and genetic variation. Population genetics theory predicts that larger populations are more likely to have higher heterozygosity and greater allelic richness. In addition, also in contrast to predictions, we did not observe more genetic diversity in populations from the regions with higher densities of populations. Even more surprising is the weak trend of increasing polymorphism with decreasing population size. We also failed to detect significant associations between population size, allelic richness, and heterozygosity. Moreover, we did not identify differences between expected and observed heterozygosity regardless of population size or isolation. Even in a predominantly outcrossing species, one would expect inbreeding to increase by $1 / 2 N_{\mathrm{e}}$ per generation. This supports the argument that present-day population sizes may not be predictive of the genetic composition of populations for a long-lived species.

In the absence of detailed historical information on each population's demographic history (such as recent population bottlenecks), our results suggest that current population size and interpopulation distance may be largely irrelevant to the maintenance and partitioning of T. reliquum genetic diversity. Instead, other factors (eg clonal reproduction, longevity) might have more important influences on the genetic structure seen among present-day populations. This notion has been further supported by the isolation by distance analysis which explained only $8.3 \%$ of the genetic differentiation among populations. Culley and Grubb (2003) also detected no relationship between genetic and geographic distance for historically fragmented populations of the perennial forest herb, Viola pubescens.

The UPGMA and hierarchical analyses suggest that associations within watersheds may be an important factor shaping genetic structure in T. reliquum. Similar evidence for such affinities was found in Mimulus caespitotus, (Ritland, 1989) and Primula sieboldii (Kitamoto et al, 2005), while Barrett et al (2004) found less clear evidence of genetic similarities among populations within river basins of a rare endemic monocot, Narcissus longispathus. The T. reliquum UPGMA phenogram displays a distinct clade of populations from the western Georgia region (Figure 2). This result at first seems surprising and contradictory. This clade includes one population (FGCH) separated by a large geographic distance, but located within the same river basin (east side of the Chattahoochee River in Georgia). In contrast, population LCCH, which is located on the western bank of the Chattahoochee River in Alabama near the western Georgia populations, is not included in this clade. Furthermore, LCCH is more similar to the two other Alabama sites within the same watershed, albeit separated by larger geographic distances. Other watersheds are represented by two to three populations each and do not provide such a persuasive pattern of watershed alliances. Although there are some exceptions (such as population ATTC and TCTC in the Oconee River basin), some populations seem haphazardously placed within a clade.

The Chattahoochee River appears to constitute a barrier for pollen and seed dispersal between populations on its eastern and western banks. The magnitude of genetic divergence between populations located east and west of the Chattahoochee River make it possible that 
these two groups of populations are from separate glacial refugia; a hypothesis we are currently investigating using $\mathrm{cpDNA}$ sequences. Such a pattern is in concordance with studies of numerous animal taxa (eg Geomys pinetis, Lepomis punctatus, Amia calva and Sternotherus minor) (Avise, 2000) and a more recently documented fungal (Septobasidium) study ( $\mathrm{T}$ Turner, unpublished). Geographic analyses of mitochondrial DNA of these taxa document consistent agreement between divergent branches of gene trees and two geographic regions: the Atlantic and Gulf zones, divided by the Chattahoochee River basin. Such phylogeographic studies suggest that shared biogeographic factors may have shaped the distributional boundaries and contemporary genetic architecture of multiple codistributed species.

The proposition that $T$. reliquum populations originated from separate glacial refugia on opposite sides of the Chattahoochee River is further supported by the disproportionate number $(50 \%)$ of private alleles in the Alabama populations, and by the abrupt change in the trend of decreasing genetic diversity $\left(H_{\mathrm{e} p}\right)$ from east to west across Georgia. The overall trend of declining genetic diversity was unexpected, especially considering the inconsistent patterns for other population genetics statistics. Furthermore, contrary to population genetics theory and the majority of empirical evidence, populations with the highest genetic diversity are located in the eastern and western extremes of the geographic range, rather than in the more centrally located populations.

\section{History of rarity - inference from genetic data}

High levels of genetic structure indicate that extant T. reliquum populations have historically experienced little genetic interchange and that there is no appreciable contemporary gene flow among these remnant populations. Populations are mostly isolated by large geographic distances and inhospitable, disturbed habitat. The high population divergence, the large number of private and rare alleles at relatively high frequencies (0.089), and significant among population heterogeneity in common allele frequencies suggest that genetic drift has historically been a major influence in shaping genetic divergence among $T$. reliquum populations. This does not appear to be the case for the more continuously distributed T. cuneatum. Although populations of $T$. reliquum and the more common $T$. cuneatum were exposed to similar anthropogenic pressures, the $T$. cuneatum populations exhibit significantly higher intrapopulation genetic variation and considerably lower interpopulation divergence. Ancient isolation affecting genetic diversity levels and patterns is the most likely explanation for the population divergence observed among contemporary $T$. reliquum populations. While T. reliquum populations have suffered greatly due to anthropogenic disturbances, our data suggest that the rarity of T. reliquum is, in all probability, of more ancient origin than previously proposed, and that this species historically existed as isolated populations long before European settlement in the south-eastern US.

For some species, there appears to be a connection between levels of genetic diversity and ecological conditions. For example, in both California and Spain, inland Avena barbata populations maintain less genetic diversity than coastal populations (Allard et al, 1978). In
Lycopersicon pimpinallifolium, the smallest populations correspond to the lowest diversity (Rick et al, 1977). For species with comparatively less variation among populations in gene diversity and effective population sizes, surveys of genetic variation may be less important. Nonetheless, there are species, T. reliquum among them, for which such ecological predictors of genetic diversity are lacking. No clear correlation has emerged from our study for a relationship between population size, isolation or marginal versus centrally located populations and genetic diversity within populations. In such cases, information about the genetic variation of individual populations, critical in guiding conservation efforts, may only be derived directly from genetic surveys. Rabinowitz (1981) proposed that while natural selection cannot select for rarity, it may favor traits which offset the disadvantages of being rare. Clonal reproduction and considerable longevity of individual $T$. reliquum ramets (many decades), combined with an outcrossing mating system, promote the maintenance of genetic variation within populations and their viability, even with declining effective population sizes.

Our results emphasize the importance of genetic surveys for the development of sound management practices and raise several issues concerning conservation strategies. One implication of our study is that $T$. reliquum might be viewed as a species composed of a number of ancient and genetically diverse populations. These populations represent units with a limited subset of genetic diversity and evolutionary potential. Such a viewpoint has relevance for the conservation of genetic resources and is important for the design of sampling strategies intended to conserve the species' genetic diversity. Our results suggest that the Alabama and nearby Georgia populations may represent different historical lineages, further reinforcing the need to protect a larger number of populations to retain the genetic diversity of this species.

\section{Acknowledgements}

Numerous people at the Georgia, Alabama and South Carolina Departments of Natural Resources and US Fish and Wildlife Service (especially Al Scholtz, Johnny Stowe and Steve Paris) were instrumental in the successful completion of this study. We particularly thank Tom Patrick, who helped with the location of all populations as well as field sampling. We are also grateful to Eva Persons and other private land owners for their collaboration and sampling assistance. We thank Mary Jo Godt, ShuMei Chang, Jennifer Cruse-Sanders, John Paul Schmidt and anonymous reviewers for valuable comments on data analyses and the manuscript. Financial support was provided by the Georgia Museum of Natural History (Joshua Laerm Award), the Georgia Native Plant Society and the Palfrey Fund, Plant Biology Department, University of Georgia.

\section{References}

Allard RW, Miller RD, Kahler AL (1978). The relationship between degree of environmental heterogeneity and genetic polymorphism. Verh K Ned Akad Wet, Afd Naturok Tweede Reeks 70: 49-69. 
Angiosperm Phylogeny Group [APG] (1998). An ordinal classification for the families of flowering plants. Ann Mo Bot Gard 85: 531-553.

Avise JC (2000). Phylogeography. Harvard University Press: Cambridge, MA.

Barrett SCH, Cole WW, Herrera CM (2004). Mating patterns and genetic diversity in the wild Daffodil Narcissus longispathus (Amaryllidaceae). Heredity 92: 459-465.

Bayer RJ, La Duke JC, Crawford DJ (1987). Isozyme variation in Trillium nivale Riddell (Liliaceae). Canad J Botany 65: 22502254.

Bohonak AJ (2002). Computer note: IBD (isolation by distance). A program for analyses of isolation by distance. J Hered 93 . 153-154.

Chakraborty R, Danker-Hopfe H (1991). Analysis of population structure: a comparative study of different estimators of Wright's fixation indices. In: Rao CR and Chakraborty R (eds) Handbook of Statistics, Vol. 8. Elsevier Science Publishers BV: New York, pp 203-254.

Cheliak WM, Pitel JA (1984). Techniques for starch gel electrophoresis of enzymes from forest tree species. Information report P1-X-42. Petawawa National Forestry Institute. Canadian Forestry Service, Agriculture, Chalk River, Ontario.

Culley TM, Grubb Jr TC (2003). Genetic effects of habitat fragmentation in Viola pubescens (Violaceae), a perennial herb with chasmogamous and cleistogamous flowers. Mol Ecol 12: 2919-2930.

Dahlgren RMT, Clifford HT, Yeo PF (1985). The Families of the Monocotyledons: Structure, Evolution and Taxonomy. SpringerVerlag: Berlin, pp 123-126 550.

Environmental Systems Research Institute [ESRI] (2002). ArcView 3.3.

Ellstrand NC, Elam DR (1993). Population genetic consequences of small population size. Implications for plant conservation Annu Rev Ecol Syst 24: 217-242.

Freeman JD (1975). Revision of a Trillium subgenus Phyllantherum (Liliaceae). Brittonia 27: 1-26.

Gemmill CEC, Ranker TA, Ragone D, Perlman SP, Wood KR (1998). Conservation genetics of the endangered endemic Hawaiian genus Brighamia (Campanulaceae). Am J Bot 85 528-539.

Gitzendanner M, Soltis PS (2000). Patterns of genetic variation in rare and widespread plant congeners. Am J Bot 87: 783792.

Godt MJW, Hamrick JL (1993). Genetic diversity and population structure in Tradescantia hirsucalis (Commelinaceae). Am J Bot 80: 959-966.

Godt MJW, Hamrick JL (1998). Allozyme diversity in the grasses. In: Cheplic GP (ed) Population Biology of the Grasses. Cambridge Univ Press: Cambridge, UK, pp 11-29.

Godt MJW, Hamrick JL (2001). Genetic diversity in rare Southeastern plants. Natl Areas J 21: 61-70.

Griffin SR, Barrett SCH (2004). Post-glacial history of Trillium grandiflorum (Melanthiaceae) in Eastern North America. Am J Bot 91: 465-473.

Hamrick JL (2004). Response of forest trees to global environmental changes. Forest Ecol Mange 197: 323-335.

Hamrick JL, Godt MJW (1989). Allozyme diversity in plant species. In: Brown AHD, Clegg MT, Kahler AL, Weir BS (eds) Plant Population Genetics, Breeding and Genetic Resources. Sinauer: Sunderland, MA, pp 43-63.

Hamrick JL, Godt MJW (1996). Conservation genetics of endemic plant species. In: Avise JC, Hamrick JL (eds) Conservation Genetics: Case Histories from Nature. Chapman \& Hall: London, pp 281-304.

Hedrick PW (1985). Genetics of Populations. Jones and Bartlett: Boston.

Jules E (1996). Yellow jackets (Vespula vulgaris) as a second seed dipsperser for the myrmecochorous plant, Trillium ovatum. Am M Nal 135: 367-369.
Karron JD (1987). A comparison of levels of genetic polymorphism and self-incompatibility in geographically restricted and widespread plant congeners. Evol Ecol 1: $47-58$.

Kitamoto N, Honjo M, Ueno S, Takenaka A, Tsumura Y, Washitani I (2005). Spatial genetic structure among and within populations of Primula sieboldii growing beside separate streams. Mol Ecol 14: 149-157.

Li CC, Horvitz DG (1953). Some methods of estimating the inbreeding coefficient. Am J Human Genet 5: 107-117.

Manchenko GP (1994). Handbook of Detection of Enzymes on Electrophoretic Gels. CRC Press: Ann Harbour, MI.

Nei M (1972). Genetic distance between populations. Am Nat 106: 283-292.

Nei M (1973). Analysis of gene diversity in subdivided populations. Proc Natl Acad Sci USA 70: 3321-3323.

Nei M (1977). F-statistics and analysis of gene diversity in subdivided populations. Ann Human Genet 41: 225-233.

Nei R, Chesser RK (1983). Estimation of fixation indices and gene diversities. Annls Human Genet 47: 253-259.

Ohara M (1989). Life history evolution in the genus Trillium. Plant Spec Biol 4: 1-28.

Peakall R, Smouse PE (2005). GenAlEx 6: Genetic Analysis in Excel. Population genetics software for teaching and research. Australian National University, Canberra, Australia. http://www.anu.edu.au/BoZo/GenAlEx.

Rabinowitz D (1981). Seven forms of rarity. In: Synge H (ed) Biological Aspects of Rare Plant Conservation. John Wiley \& Sons Ltd: New York, pp 205-217.

Rick CM, Fobes JF, Holle M (1977). Genetic variation in Lycopersicum pimpinellifolium: evidence of evolutionary change in mating systems. Pl Syst Evol 127: 139-170.

Ritland K (1989). Genetic differentiation, diversity, and inbreeding in the mountain monkeyflower (Mimulus caespitosus) of the Washington Cascades. Can J Bot 67: 2017-2024.

Rohlf FJ (1992). NTSYS-pc. Numerical Taxonomy, Multivariate Analysis System. Exeter Software: Setauket, NY.

Rousset F (1997). Genetic differentiation and estimation of gene flow from F-statistics under isolation by distance. Genetics 145: 1219-1228.

Schoen DJ, Brown AHD (1991). Intraspecific variation in population gene diversity and effective population size correlates with the mating system in plants. Proc Natl Acad Sci USA 88: 4494-4497.

Sokal RR, Rohlf FJ (1981). Biometry, 2nd edn. Freeman: New York.

Soltis DE, Haufler CH, Darrow DC, Gastony GJ (1983). Starch gel electrophoresis of ferns: a compilation of grinding buffers, gel and electrode buffers, and staining schedules. Am Fern J 73: 9-27.

Tomimatsu H, Ohara M (2003). Genetic diversity and local population structure of fragmented populations of Trillium camschatcense (Trilliaceae). Biol Conserv 109: 249-258.

Wang ZF, Hamrick JL, Godt MJW (2004). High genetic diversity in Sarracenia leucophylla (Sarraceniaceae), a carnivorous wetland herb. J Hered 95: 234-243.

Weir BS, Cockerham CC (1984). Estimating F-statistics for the analysis of population structure. Evolution 38: 1358-1370.

Wendel JF, Parks CR (1982). Genetic control of isozyme variation in Camillia japonica L. J Hered 73: 197-204.

Whitkus R, Bryan FA, Les DH, Tyrrell LE (1987). Genetic structure in a heterocyanic population of Trillium sessile (Liliaceae). Plant Species Biol 2: 67-73.

Workman PL, Niswander JD (1970). Population studies on southwestern Indian tribes. II. Local genetic differentiation in the Papago. Am J Hum Genet 22: 24-49.

Wright S (1922). Coefficient of inbreeding and relationships. Am Nat 56: 330-338.

Wright S (1951). The genetical structure of populations. Ann Eugenics 15: 323-354. 